\title{
Citizen Disaster Science Education for effective disaster risk reduction in developing countries
}

Rishi Ram Parajuli

\begin{abstract}
This paper briefly discusses on the recent scenario in sustainable development goals and disaster risk reduction initiatives. Recent reports state that achievement of the target of SDG on 2030 is questionable however several strategies are placed internationally and locally. It raises the issue on paradigm shift in public awareness through citizen disaster science education, which will provide basic science behind any disaster of their locality that help in taking decisions in reducing exposure, improving preparedness and reaction, response and recovery to any disaster.
\end{abstract}

Keywords: Disaster risk reduction, Citizen science, Community participation, Sustainable development goals

\section{Introduction}

Climate change, rapid urbanization and infrastructure development trends push the global community toward higher exposure to natural hazards. The Sustainable Development Goals (SDG) Report 2019 points out that "The world is not on track to end poverty by 2030" (United Nations 2019a). It further mentions that fatalities and economic losses due to natural disasters are concentrated in low and middle-income countries. As well as claiming lives and damaging infrastructure, natural disasters also impact food supply, dragging more people under the poverty line in developing and underdeveloped countries. However, there are several strategic frameworks that can be utilised on a national and international level that can help move regions and countries toward the target of SDG 2030 with corresponding indicators (United Nations 2018).

The United Nations Office for Disaster Risk Reduction (UNDRR) defines Disaster Risk Reduction (DRR) as aiming to "reduce the damage caused by natural hazards like earthquakes, floods, droughts and cyclones, through an ethic of prevention". DRR comprises of several

Correspondence: rishi.parajuli@bristol.ac.uk

Department of Civil Engineering, University of Bristol, Queens Building, University Walk, Bristol BS8 1TR, UK

\section{Springer Open}

disciplines, such as disaster management, mitigation and preparedness, which all align with the principle of sustainable development (UNISDR 2015). Global and local initiatives are being implemented through the Sendai Framework for DRR (SFDRR) to achieve SDG (United Nations 2015). The UNISDR Strategic Framework 2016-2021 sets out seven global targets which involve reducing: casualties, affected number of people, economic loss and damage to critical infrastructure, whilst improving: strategies to target indicators, international cooperation and access to early warning and risk assessment (UNISDR 2016). Recently published guidance from the UNDRR delineates from the SFDRR, focusing on local disaster risk reduction and resilience which explains the localization of DRR through the principle of sustainable development (UNDRR 2019). The guidance further points out several essential areas of knowledge, which include disaster risk perception, preparedness, response and recovery in institutional and community level.

Figure 1 shows a summary of the major engagement and components that must be considered on an individual, community and institutional level for DRR. Two major parts of DRR are risk assessment and early warning under preparedness and awareness. This helps 


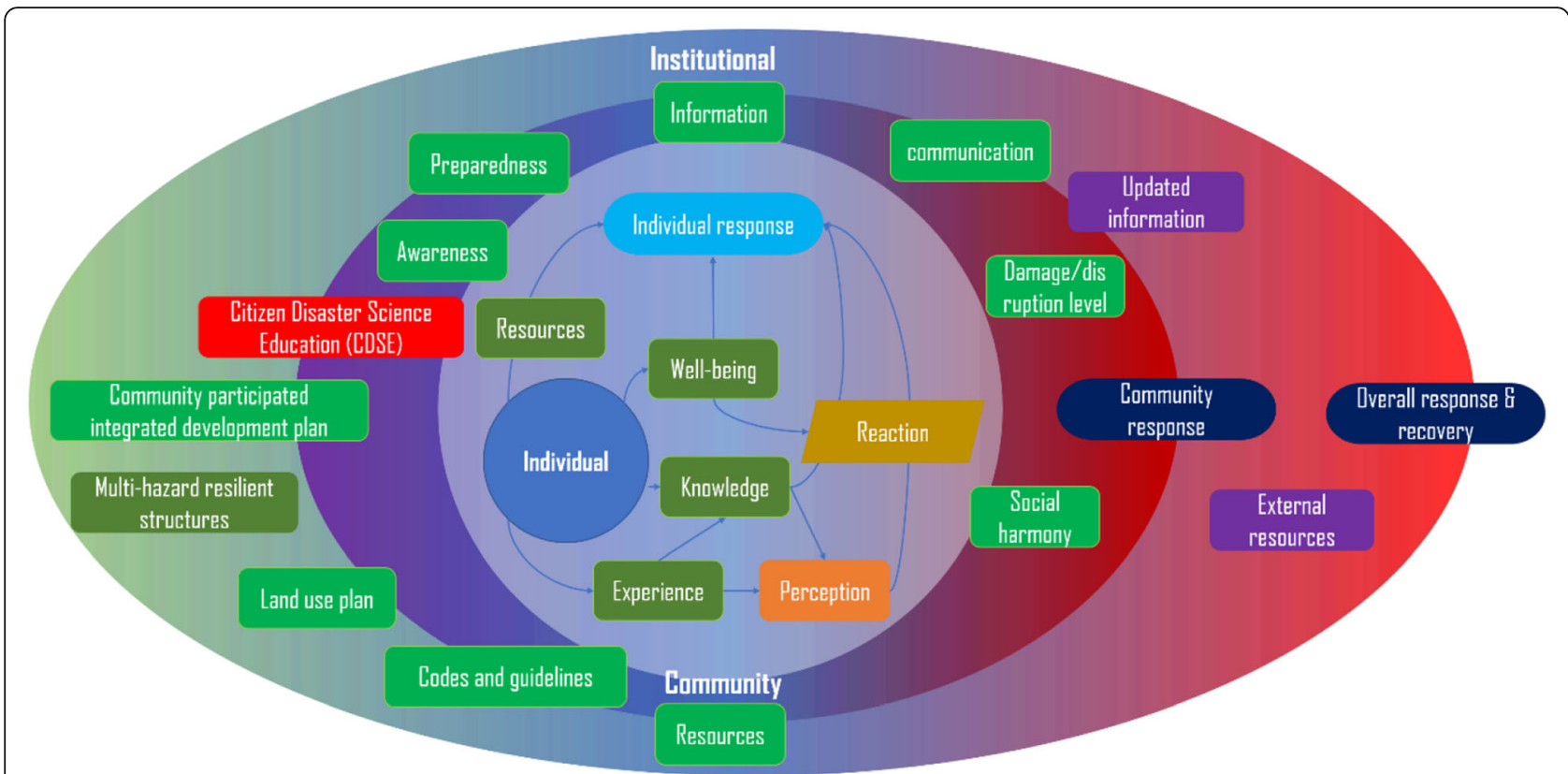

Fig. 1 Eye diagram of components of disaster risk reduction with individual, community and institutional level engagement for pre-disaster, during and post-disaster scenarios

individuals and communities to be prepared, enabling fast evacuation during disaster events and equipping key stakeholders to plan for rapid response and recovery. Knowledge is the key component which informs decision-making when reducing risk and improving preparedness in the pre-disaster phase, and also when enhancing perception, reaction and response during and post-disaster. There are several early warning systems that exist around the globe for different types of disaster events (e.g. earthquake, flood, landslide, fire etc.) (United Nations 2019b), however the effectiveness of these measures often do not achieve the level anticipated.

\section{Challenges and gaps in DRR implementation}

In 2019, floods in South Asia have claimed hundreds of lives in Nepal (Government of Nepal 2019), India and Bangladesh. Every year, torrential rain in the monsoon months of July and August bring with it associated landslides and floods which ruins society through fatalities, infrastructure damage and economic loss. Flood disaster risk reduction is much supported by technology, where the predication, forecast and data collection are relatively easy and effective (McCallum et al. 2016). Even though institutional DRR is on the right track, these negative consequences are not reducing, but rather soaring each year. The Department of Hydrology and Meteorology (DHM) of Nepal in coordination with the National Emergence Operation Center (NEOC) under Home Ministry issues information, advice and early warnings about heavy rainfall and floods through their website, local media, social media and bulk SMS. The NEOC office is open $24 \mathrm{~h}$ and targets local community and stakeholders (DHM 2019). Response and recovery on an institutional level is improving but there are gaps in the individual and community level which derail the goal of DRR.

The Gorkha Earthquake sequence 2015 is another big disaster event which was supposed to hit the region in the meantime even though the exact forecasting of earthquake is not possible. There were several organizations involved in advocating the DRR, have several programs conducted through government and nongovernmental organizations, even though one study found that the perception and preparedness state for disaster prevention education is not properly placed (Tuladhar et al. 2015). The long period dominant ground motion of Gorkha earthquake resulted relatively low damages in low rise buildings (Parajuli and Kiyono 2015), however, several other factors also contributed in structural damage (Sharma et al. 2017; Wang et al. 2016). Major themes of earthquake safety endorsed by all institutions and media were 'HIDE UNDER THE TABLE or BED' and 'DROP, COVER \& HOLD'. These simply aware the people what to do during the earthquake, but people never know under which conditions these actions should follow. Hence, few cases were known, where, people who were in the veranda of their home, rush into their structurally weak house to hide under the table or bed. Among them, author had met with a teacher in Thanapati, Nuwakot, whose mother 
lost her life running into her two storied stone masonry house to hide under the bed from outer veranda during shaking, even though she can easily escape to open ground.

Human and institutional behaviour have the largest impact on the response and recovery of any disaster event (Richard Eiser et al. 2012), which directly affects the effectiveness of early warning measures (Aerts et al. 2018). The initial shock due to any disaster may vary in time span, but the risk perception, interpretation, reaction and response all vary individually with each disaster. Interviews and experiments with drivers regarding the action taken during and just after the earthquake show the similar phenomenon (Parajuli 2017).

Six hundred seventeen million of people lack minimum proficiency and 750 million adults are illiterate all over the world (United Nations 2019a). Moreover, formal literacy would not necessarily provide proper knowledge in disaster science, which had also reported in the study from Kenya (Okayo et al. 2015). Hence, the lack of proper disaster science knowledge pushes the global community towards more exposure, high risk and delayed response and recovery. Insufficient hardware measures (e.g. shelters, lifelines) that supplement the software measures (e.g. early warning) is another factor that hinders effective DRR.

Hence, a paradigm shift in planning and implementing DRR is essential in international and national strategies. Knowledge in holistic disaster scenarios should be increased among actual citizens, which would ultimately motivate and enable them to reduce their own exposure and risk, instead of solely relying on law enforcement. Multidisciplinary participatory approach in local level resilience assessment would better suggest the state of community strength along with their awareness and perception (Parajuli et al. 2020).

\section{Moving forward through "Citizen Disaster Science Education"}

Citizen Disaster Science Education (CDSE) could be an effective way to enhance disaster education in developing countries. CDSE will cover the basic science behind the major disasters, their consequences, and the appropriate responses and application of measures. This can be done through a variety of methods and mediums, (e.g. print, audio, video) translated into the local language that is easy to understand. This should be targeted at all age groups instead of school or college students only. CDSE will help people understand disaster risks properly, which will guide them to make decisions to reduce exposure. Increased disaster risk knowledge will not only help their perception, reaction and response, but can also provide a qualitative source of crowd data along with their feeling of engagement in disaster risk management. Community participation in integrated development plans will be more effective when their broader perspectives are reflected.

Figure 2 shows the conceptual sketch on community performance with and without CDSE, representing by yellow and red lines respectively. Generally, disaster and recovery period can be categorized in three major stages, the first is the duration of the direct hit by disaster on the community, can be represented as the disaster event period $\left(\mathrm{T}_{\mathrm{e}}\right)$. This period varies on disaster types, single event earthquake may have short time period, but flood may strike for longer period. The second stage covers the transition time between disaster event period and the institutional recovery start time, which can be represented as the transition period $\left(\mathrm{T}_{\mathrm{t}}\right)$, total recovery time $\left(\mathrm{T}_{\mathrm{r}}\right)$ is the time taken to bring back the community to at least the previous level through integrated community and institutional efforts. CDSE could control further sinking down of the community performance, where losses will be minimized in all stages of disaster and

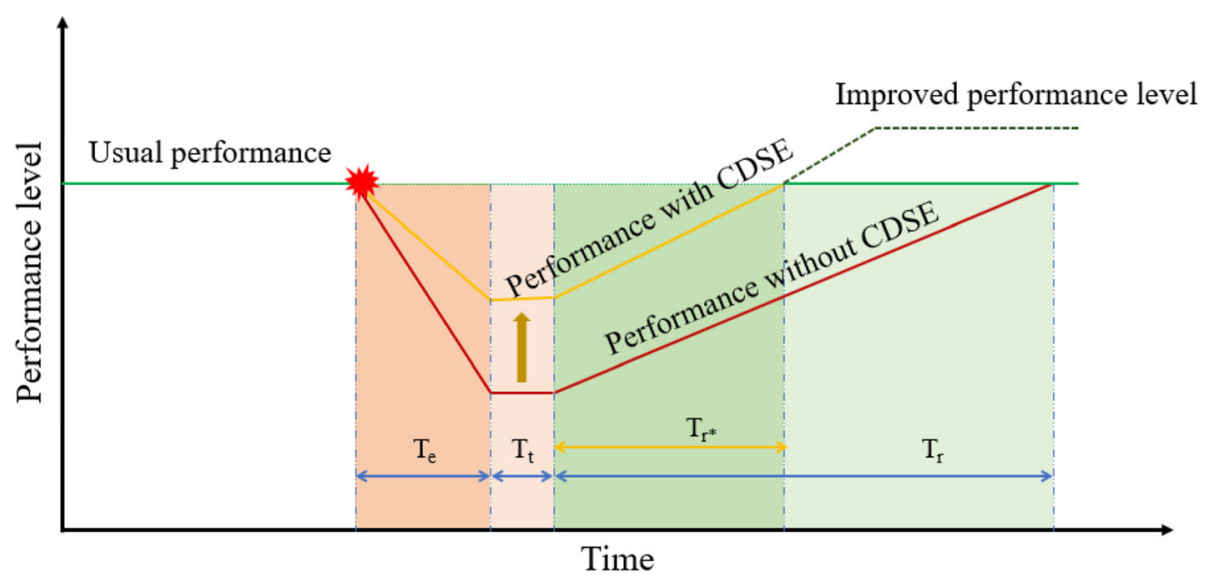

Fig. 2 Conceptual sketch on improvement of community performance due to community disaster science education 
recovery. Proper knowledge on disaster characteristics and consequences and corresponding reaction and response in local level; understanding and coordination with other institutions from local level could shorten the cumulative total recovery period to $\mathrm{T}_{\mathrm{r}^{*}}$ to reach to the normal performance level. However, the higher resiliency due to CDSE would help community to jump to improved performance level in post disaster scenario.

Recent practice of awareness programs has not been enough in penetrating local community in understanding disasters and its consequences. Now, strategic plans should be placed in fostering effective DRR to achieve proper local impact. CDSE would be the effective way in strengthening the individual and community, ultimately supporting the targets of SDG.

\section{Acknowledgements}

Author would like to thank Jitendra Agarwal, Anastasios G. Sextos and two anonymous reviewers for their comments and suggestions.

\section{Authors' contributions}

Parajuli RR has conceptualized and prepared the article. The author read and approved the final manuscript.

\section{Funding}

Not applicable.

\section{Availability of data and materials}

All the data and materials used are mentioned in the article.

\section{Competing interests}

Author of this article has no conflict of interest. Also the author needs to ensure that they are responsible for any conflict of interest that may arise. Also the researcher has not received any fee for patents of the manuscript. Concerning non-financial computing interest the author encourages the manuscript has significant value for intellectual and/or academic purposes on the fields.

Received: 13 January 2020 Accepted: 27 March 2020

Published online: 03 April 2020

\section{References}

Aerts JCJH, Botzen WJ, Clarke KC, Cutter SL, Hall JW, Merz B, Michel-Kerjan E, Mysiak J, Surminski S, Kunreuther H (2018) Integrating human behaviour dynamics into flood disaster risk assessment. Nat Clim Chang 8(3):193-199

DHM. 2019. "Hydrology." Retrieved (http://www.hydrology.gov.np/)

Government of Nepal. 2019. "Nepal Disaster Risk Reduction Portal." Retrieved July 25, 2019 (http://drrportal.gov.np/)

McCallum I, Liu W, See L, Mechler R, Keating A, Hochrainer-Stigler S, Mochizuki J, Fritz S, Dugar S, Arestegui M, Szoenyi M, Bayas JCL, Burek P, French A, Moorthy I (2016) Technologies to support community flood disaster risk reduction. Int J Disaster Risk Sci 7(2):198-204

Okayo J, Odera P, Omuterema S (2015) Socio-economic characteristics of the community that determine ability to uptake precautionary measures to mitigate flood disaster in Kano Plains, Kisumu County, Kenya. Geoenvironmental Disasters 2(26)

Parajuli RR (2017) Dynamic Bhavior of vehicles during an earthquake. Kyoto University, Kyoto. https://doi.org/10.14989/doctor.k20346

Parajuli RR, Agarwal J, Xanthou M, Sextos AG (2020) Resilience of Educational Communities in Developing Countries: A Multi-Disciplinary Approach. In: 17th World Conference on Earthquake Engineering, Sendai, Japan.

Parajuli RR, Kiyono J (2015) Ground motion characteristics of the 2015 Gorkha earthquake, survey of damage to stone masonry structures and structural field tests. Frontiers in Built Environment 1:23

Richard Eiser J, Bostrom A, Burton I, Johnston DM, McClure J Paton D, van der Pligt J, White MP (2012) Risk interpretation and action: a conceptual framework for responses to natural hazards. Int J Disaster Risk Reduct 1(1):516

Sharma K, Subedi M, Parajuli RR, Pokharel B (2017) Effects of surface geology and topography on the damage severity during the 2015 Nepal Gorkha earthquake. Lowloand Technol Int 18(4):269-282

Tuladhar G, Yatabe R, Dahal RK, Bhandary NP (2015) Disaster risk reduction knowledge of local people in Nepal. Geoenvironmental Disasters 2(1)

UNDRR (2019) Local disaster risk reduction and resilience: words into action, Geneva

UNISDR. 2015. "What is disaster risk reduction?". Retrieved (http://www.unisdr.org/ who-we-are/what-is-drr)

UNISDR (2016) UNISDR strategic framework 2016-2021, Geneva

United Nations (2015) Sendai framework for disaster risk reduction 2015-2030, Geneva

United Nations (2018) Global Indicator framework for the sustainable development goals and targets of the 2030 agenda for sustainable development, Geneva

United Nations (2019a) The sustainable development goals report 2019, Geneva

United Nations. 2019b. "United Nations climate change summit 2019." Retrieved (https://www.un.org/en/climatechange/cop24.shtml)

Wang F, Miyajima M, Dahal R, Timilsina M, Li T, Fujiu M, Kuwada Y, Zhao Q (2016) Effects of Topographic and Geological Features on Building Damage Caused by 2015.4.25 Mw7.8 Gorkha Earthquake in Nepal: A Preliminary Investigation Report. Geoenvironmental Disasters 3(1):1-7

\section{Publisher's Note}

Springer Nature remains neutral with regard to jurisdictional claims in published maps and institutional affiliations.

\section{Submit your manuscript to a SpringerOpen ${ }^{\circ}$ journal and benefit from:}

- Convenient online submission

- Rigorous peer review

- Open access: articles freely available online

- High visibility within the field

- Retaining the copyright to your article

Submit your next manuscript at $\boldsymbol{\nabla}$ springeropen.com 